\title{
DETERMINISMO Y LIBERTAD EN EL MATHEMATICUS DE BERNARDO SILVESTRE
}

\author{
Francisco Tauste Alcocer \\ Profesor de Filosofía
}

\section{RESUMEN}

En este artículo se intenta poner de manifiesto un problema que ha preocupado mucho a los que en la Antigüedad trataron los temas astrológicos: ¿puede el ser humano desafiar una predicción suicidándose? La historia del Patricida, recuerda Edipo, trata de mostrar la complejidad de toda posible respuesta a la pregunta. Pero siempre queda al ser humano la posibilidad última de sustraerse al curso de los acontecimientos tratando de imponer su voluntad frente al destino de los astros: ésta es la lección del Mathematicus acorde con el humanismo de Chartres.

\begin{abstract}
Destiny and liberty in the Mathematicus of Bernard Silvestrus. This paper attemps to reveal a problem that worried a lot to people who dealed with astrological themes in antiquity. Can human being challenge a prediction by committing suicide? Patricida's story, which remembers Oedipus, tries to point out the complexity of reponse. But human being always has the last possibility to elude the rum of events by imposing his will on star's destiny: this is the Mathematicus's lesson in conformity with the chartrian humanism.
\end{abstract}

La problemática astrológica siempre fue vista con cierta prevención en los ambientes intelectuales cristianos de la Antigüedad tardía no sólo porque representaba un fuerte competidor con la Providencia, comò ya trató Boecio de significar según su enfoque concordista, ${ }^{1}$ sino también porque hacía inviable todo intento de aproximación a la libertad del ser humano. Por ello no es extraño que a mediados del siglo XII, ese siglo tan rico en la asimilación de las doctrinas antiguas que vienen a Occidente sobre todo a través de los pensadores árabes, un poeta filósofo como Bernardo de Tours o Bernardo Silvestre escriba un poema de 425 dísticos elegíacos donde, tomando como argumento un tema desarrollado por el Pseudo-Quintiliano en su Declamatio Maior $I V$, se plantea el conflicto existente entre el Destino astral y la libertad del

1 Cfr. Boecio Philosophiae Consolatio Lib. IV (Corpus Christianorum)

2 Vid. G. Lehnert Quintiliani quae feruntur Declamationes XIX maiores.Leipzig. 1905, págs. 356 ss. 
individuo llegando a formular una pregunta que resume muy bien el problema: ¿puede el ser humano desafiar una predicción astrológica suicidándose? o, dicho de otra forma, ¿es posible engañar el curso de la fortuna a través del suicidio?

Poco importa que la respuesta quede en el aire en una pieza inacabada y llena de ambigüedades, ${ }^{3}$ pero el problema está planteado con toda su fuerza: ¿podemos los seres humanos vernos libres alguna vez de la tiranía del Destino? En el caso de que atisbemos una posible respuesta afirmativa, cabría seguirse preguntando, ¿cómo podemos hacer frente a las leyes inmutables del mundo superior?

El argumento del Mathematicus, que nos recuerda en gran medida la historia de Edipo, es una narración muy típica de la época helenística: un matrimonio mayor y sin hijos compuesto por un caballero romano y su esposa viven felices pero desean tener descendencia para alcanzar la dicha perfecta, y para ello consultan a un astrólogo que les profetiza que tendrán un hijo muy perfecto: se parecerá a Paris en belleza, a Aquiles por su heroismo y a Ulises por su prudencia. Este hijo llegará a ser el rey de los romanos pero también está destinado a matar a su propio padre.

Al oír esta parte final de la profecía, el marido rechaza su deseo inicial de tener descendencia pero, a pesar de ello, yacen juntos y la mujer queda embarazada. El esposo manda a su mujer que mate al hijo nada más nacer, pero cuando ella ve que ha dado a luz un niño tan bello, lo entrega en secreto a unos padres adoptivos.

El niño, que recibe el nombre críptico de Patricida, va creciendo y se va educado de acuerdo con el programa clásico de las artes liberales hasta llegar a iniciar el camino de las armas. Participa en las luchas contra los cartagineses, obteniendo finalmente una gran victoria que le vale para ser proclamado rey de los romanos por aclamación popular, previa la abdicación del monarca anterior, que se muestra muy agradecido de que lo haya devuelto a casa sano y salvo.

La madre, sabiendo que había llegado a tan alto puesto y luchando interiormente entre su papel de madre y esposa, revela la verdad a su marido, el cual acepta de buen grado el desarrollo del Destino y muestra grandes deseos de abrazar a su hijo, sabiendo de antemano que puede ir a una muerte segura, según la profecía del astrólogo.

La madre tiene un encuentro muy emotivo con su hijo y posteriormente el padre, que declara estar dispuesto a dejarse matar por él con el fin de dar cumplimiento al vaticinio astrológico: «Mátame, hijo, aunque en tu corazón lo aborrezcas; así se cumplirá el Destino», viene a decirle el padre. Pero el hijo rechaza la tiranía de un Destino que se impone a su voluntad. Por ello convoca al Senado y le pide que le conceda el privilegio especial de poder suicidarse. El Senado rechaza esta decisión y mientras está deliberando entristecido por la situación planteada, el Patricida decide dejar de ser rey y así, a través de esta opción totalmente libre queda fuera de la acción de la profecía. En este punto se interrumpe el poema de forma un tanto abrupta.

3 Sobre la ambiguiedad del Mathematicus, vid. Godman, P. «Ambiguity in the Mathematicus of Bernardus Silvestris» Studi Medierali (1990), pp. 583-648. 
Lo que está en el fondo de este argumento no es un simple problema humano que pueda servir de base a un ejercicio retórico sino una auténtica cuestión metafísica cuya solución es abordada desde el integumentum, es decir, desde una estrategia literaria. Ésa era la costumbre seguida por muchos autores chartrianos como Bernardo Silvestre al abordar problemas filosóficos y teológicos de difícil solución con los recursos propios del lenguaje literario, especialmente el lenguaje alegórico. Así se intentaba resolver ambiaguamente lo que resultaba difícil hacerlo a través de un discurso estrictamente filosófico.

En este caso se trataba de un asunto metafísico lo suficientemente intrincado como para no poseer una solución última y definitiva: las relaciones entre el determinismo astral y la libertad humana. Por ello, y dentro del programa de concordia doctrinal trazado por los autores chartrianos, nuestro autor no desea abordar directamente y a fondo el problema en cuestión sino más bien subrayar su aspecto más dramático y conflictivo, sobre todo desde la lógica de los sentimientos humanos.

Nosotros seguiremos la misma pauta en esta comunicación: no abordaremos directamente los aspectos metafísicos y antropológicos del problema sino que nos limitaremos a aprovechar el texto del Mathematicus como una fuente historiográfica de primera mano para poder profundizar mejor en la visión que tenía Bernardo Silvestre de la influencia astrológica.

Este matrimonio mayor sin hijos vive en una Roma bastante anacrónica: un reino, en un ambiente totalmente pagano donde el imperio de la Fortuna es comúnmente aceptado por todos:

«Sors arrisit eis, favit Fotuna, beati

Omnibus, excepto munere prolis, erant»(vv.23-24)

Por ello consultan a un astrólogo, ya que quieren saber qué destino les espera de acuerdo con el orden superior de los astros:

«Spemque super dubiam quid fati volverat ordo

Certior esse volens consulit astrologum,

Qui poterat stellis superum deprendere curas,

Parcarum mentem consiliumque Jovis» (vv. 37-40)

El fundamento racional de este orden astrológico es de naturaleza matemática: «astra movent numeri» (v. 44). Por tanto, si tenemos un conocimiento profundo de estos números celestes, estamos en condiciones de comprender ese orden del universo que manifiesta su voluntad en cada momento a través de los movimientos astrales.

4 Citamos por la edición de B. Hauréau Le Mathematicus de Bernard Siliestris et la Passio Sanctae Agnetis de Pierre Riga.París, 1895.(En adelante sólo pondremos entre paréntesis el número de los versos citados). Aparte de la otra edición de peor calidad en la Patrología de Migne PL 171, col.1365-1380, en 1988 se tradujo al inglés como parte de una tesis doctoral inédita: Stone, D. The Mathematicus of Bernardus Siliestris. Sydney, 1988. 
Por eso, los únicos que garantizan la verdad de la predicción astrológica son los diosesastros que configuran ese orden superior que para un pagano de la Antigüedad tardía se confundían con lo divino:

«Fata tibi spondent, Di spondent, sidera spondent;

Res rata quam spondent sidera, fata, Dii» (vv.81-82)

El saber astrológico representaba en este momento una forma de conocimiento científico heredado de la tradición caldeo-babilónica cuyo objetivo fue la unión de la matemática astronómica y la religión astral. ${ }^{5}$ Por ello no resulta extraño que dentro del plan de aprendizaje del Patricida destaquen especialmente sus incursiones en el campo de la astrología, con la que mantiene una relación muy estrecha la música y la matemática por formar parte de un mismo campo disciplinar. ${ }^{6}$

Esta unión entre la religión pagana y la práctica astrológica configura una nueva cosmovisión en la época helenística bajo el respaldo del estoicismo y el platonismo medio, pero esta religiosidad astral ya se venía gestando desde el libro X de las Leyes, el Epínomis y el propio Timeo.

Es el concurso de los dioses olímpicos y de ese «ordo fatalis» del mundo superior el que ha hecho posible que nuestro héroe, el Patricida, acabe su periodo de formación escolar e inicie la carrera militar llegando a ser nombrado «Ausonii signifer imperii»,

«Pugnat ad hoc Lachesis, super hoc Fortuna laborat,

Comprobat hic vires Juppiter ipse suas;

Et quia sic fieri fatalis postulat ordo,

Hanc sibi regandi fata dedere viam» (vv. 149-152)

Toda su trayectoria biográfica no es producto ni del azar ni de su propio esfuerzo sino fundamentalmente de la Fortuna. Aceptar esto implica por nuestra parte relativizar de manera humilde nuestra propia existencia, teniendo en cuenta otra dimensión diferente de los asuntos humanos:

5 Cfr. las obras de Neugebauer y Cumont, especialmente Neugebauer, O. The Exact Sciences in the Antiquity: Providence, 1957 y Cumont, F. Le Mysticisme astral dans l'antiquité, 1909

6 «Novit enim quam sideribus, quam primitus orbi

Sementem dederit materiamque Deus;

Quae fecit in rebus ratio, quae causa creandis;

Quos habeant nexus, quas elementa vices;

Et numeri quo fonte fluant, qua lege ligentur,

Quo sibi conveniant schemate dispositi;

Musica quo numero, vel qua sibi proximitate

Dissimiles jungat consociatque sonos

Astra quibus spatiis distent septena planetae» (vv. 117-125) 
«Ridiculos hominum versat sors caeca labores:

Saecula nostra jocus ludibriumque Deis» (vv. 175-176)

Conforme se van desarrollando los acontecimientos de su existencia que culminan en su designación como rey de los romanos, vamos viendo confirmada en el Patricida la profecía del astrólogo hasta el punto que su madre queda estupefacta al comprobar la exactitud de su cumplimiento.

$\mathrm{Y}$ cuando decide ir a verlo para abrazarlo hay en ella una guerra interior entre sus deberes como esposa y su amor de madre, una guerra impuesta por el Destino que no puede eludir:

«Si queat aeterno Parcas evertere cursu,

Vellet pro domino fata subire suo.

Sed tristis Lachesis, sed inexorabile fatum,

Non nisi praescriptas ius habet ire vias» (vv.297-300)

Al descubrir a su marido toda la verdad sobre su hijo, no puede menos que reconocer que las palabras del astrólogo se han cumplido hasta este momento, y que ahora hay que afrontar el final de la profecía: la muerte del padre fijada de antemano por el Destino:

«Verba mathematici, nisi quod tua fata supersunt,

Omnia decreto fine peracta vides;

Currentesque suo fataliter ordine stellae

Et tua defixo fata tenore trahent» (vv. 393-396)

Pero el marido no se arredra ante un destino tan funesto y, como el héroe trágico, sale a su encuentro dispuesto a aceptarlo, ya que no será su hijo quien lo mate sino una fuerza superior determinada por el orden de los astros. Por otra parte, vale la pena morir para renacer en su hijo que ha llegado a la culminación de su carrera militar:

«Sed moriens ego non moriar, totusque superstes

Totus et in tali prole renatus ero.

Quod de fatali descendit origine rerum

Non dicas fieri fraude vel arte tua;

Fatum me perimit, fatum servavit eumdem

Quem servasse putas; omnia lege meant» (vv. 437-442)

Todo se desenvuelve, pues, de acuerdo con una ley inexorable expresada a través de los astros, que nadie puede evitar o desobedecer. Por esta ley superior los padres han podido conocer de antemano los éxitos de su hijo:

«Filii, cuius opes, sapientia, forma, potestas,

Sunt mihi sidereis significata notis»(vv. 493-494) 
Por ello el padre, al comprobar que no pueden cumplirse sus deseos iniciales de eliminar al Patricida sino que, más bien, ha de aceptar los éxitos de éste ya previstos en la profecía, no tiene más remedio que reconocer que el artífice final de todo lo sucedido ha sido el Destino, ese orden que está por encima de cualquier obra humana:
«Ordo sed aeternus praefixaque nexio rerum
Humanae vanum dissipat artis opus,
Servaturque puer placide qui temperet orbem
Romuleaque regat moenia facta manu» (vv. 543-546)

Porque si está previsto que el Patricida mate a su padre no es en virtud de su propio deseo de hacerlo sino de acuerdo con una fuerza superior que se le impone y le obliga a matar; por tanto el culpable, si cabe utilizar esta expresión, es el Destino:

«Vi firmamenti divinorumque supernis
Motibus astrorum cogeris esse nocens;
Cogeris esse nocens manifestaque culpa deorum
Est ut non possis mitior esse patri» (vv. 583-586)

Y el padre, en un gesto supremo propio de la tragedia, acepta la muerte que le prepara el Destino por medio de su hijo, cuyo comportamiento, a su juicio, es el de ser mero instrumento de una ley establecida $a b$ aeterno:

«Filii, me perimes, immotaque pensa sororum

Istud ab aeterno constituere scelus.

Olim dispositi lex et violentia fati

Utetur manibus in mea fata tuis» (vv. 577-580)

Por otra parte, el Patricida es consciente de que por encima de su voluntad el Hado ha querido manchar su vida con actos que él mismo no desea aceptar. Pero conoce al ambiguo discurrir de la Fortuna: unas veces te eleva a cumbres insospechadas y otras te arrastra a los infortunios más crueles. Pero, ¿cómo podemos reaccionar los humanos en estos casos extremos cuando resulta que parecemos un juguete en manos del Destino? ¿Existe en nosotros una fuerza especial capaz de imponer nuestra voluntad al orden determinista de los astros? Como ha reconocido Peter Dronke, ${ }^{7}$ las respuestas a estas preguntas hay que encontrarlas en ese optimismo sobre la condición humana propio de los autores chartrianos, pero especialmente de Bernardo Silvestre, para el que lo mejor del ser humano es su capacidad de ser libre y soberano no sólo sobre sí mismo sino también sobre los astros y las leyes de la naturaleza. Y la explicación última de esta libertad reside según la tradición judeo-cristiana en nuestra semejanza

7 Dronke, P. Fabula:Explorations into the uses of Myth in Medieval Platonism.Leiden, 1974. (Cap.IV Fables of Destiny, pág. 138) 
con la divinidad: he ahí una razón de la dignidad humana que está prefigurando la Oratio de un Pico della Mirandola:

«Frustra particulam divinae mentis habemus,

Si nequeat ratio nostra cavere sibi.

Sic elementa Deus, sic ignea sidera fecit,

Ut neque sideribus subditus esset homo;

Sed puri datur ingenii solertis maior

Possit ut obiectis obvius esse malis» (vv.641-646)

No podemos decir que Bernardo Silvestre nos haya resuelto el problema teórico de las relaciones entre determinismo y libertad sino que más bien se ha desmarcado de una explicación excesivamente pagana por fatalista, utilizando como elemento contrastador la visión cristiana de la libertad. Pero lo que tiene difícil solución en el plano teórico, puede tenerla más fácilmente en el plano literario. Y ésta será la tarea de Bernardo en su poema: tratar a través de un procedimiento narrativo de resolver el conflicto interior del Patricida.

Efectivamente, en su intervención final ante el Senado plantea la posibilidad de escapar al Destino a partir del uso de su propia libertad. Es cierto que no tiene claro cómo se va a materializar este enfrentamiento con el Hado, por ello su propuesta resulta ambigua («postulat ambiguum munus» v. 666) pero él no desfallece y trata a través de una serie de tentativas de escapar de la influencia de la profecía astrológica. ¿Cómo? Dejando de ser rey. De ahí esa petición que se repite muchas veces a lo largo de su parlamento ante el Senado:

«Per superum, per si qua manet reverentia nostri,

Quidquid id est, regi porrig, Roma, tuo»(vv.676-677)

Aunque, en una segunda intervención ante la misma asamblea concretará mucho más su petición:

«Sed peto quod duro posset ab hoste dari:

Ut liceat propriamque mihi consciscere mortem

Et miseram vitae praecipitare diem» (vv. 739-741)

El Patricida sólo busca una libertad: quiere la libertad de suicidarse («vult libertatem mortis habere suae», v. 747). Eso es lo que solicita del Senado: dejar esta vida para poder alejarse de este Destino que le sujeta y esclaviza. Aparecen en esta parte del poema los motivos platónicos del abandono de este mundo tan propios del Fedón:

«In terram terrena caro, mens ignis ad ignem,

Ad speciem redeat portio quaeque suam.

Corporis invisi caecis excedere claustris

Non trepidat meritis mens mea tuta suis. 
Carnis ab excessu superos migrabit ad axes,

Sideris in numerum restituenda sui» (vv. 798-803)

El Senado se queda perplejo ante semejante petición. No es algo que una institución tan alta pueda fácilmente conceder. Parece que no esté en su mano dar el consentimiento al suicidio del Patricida, por más argucias retóricas que se utilicen. Pero nuestro héroe sigue sin arredrarse, y ante las vacilaciones de los senadores propone, en un gesto espontáneo y original, dejar el cargo de rey y marcharse libremente a realizar su propio destino, no el que le imponen los astros:

«Si, quia muneribus vestri fungatur honoris

Rex ideo vester desinit esse suus,

Pono citus trabeam, vestrum citus exuo regem,

Liber et explicitus ad mea vota meus»( vv. 852-855)

Si el suicidio resulta demasiado violento para que un Senado pueda consentirlo, no sucede lo mismo con la abdicación, porque, en definitiva, de lo que se trata es de salirse del campo de influencia de la profecía, y para ello no hace falta morir sin dejar de ser rey. Así, abdicando el Patricida recupera su libertad sin tener que haber recurrido a la instancia suprema del suicidio que, según Platón, no es la mejor manera de abandonar este mundo. ${ }^{8}$

A pesar de esta pirueta literaria final que evita un desenlace trágico para todos y hace que el poema acabe felizmente, todavía podemos seguir afirmando que el problema filosófico de fondo queda sin resolver, pero éste es quizá el destino de los problemas filosóficos de siempre, el de estar condenados a no salir de su mera formulación interrogativa. Y si la razón se muestra incapaz de decir la última palabra sobre un asunto tan grave, la imaginación literaria construye sus integumenta y busca la forma de dar salida a algo que no la tiene. La misión de la poesía es como la de un deus ex machina en la tragedia clásica: intentar que las cosas acaben de la mejor manera posible, no por huir de desenlaces funestos sino por alentar desde el calor de la literatura la creencia en la creatividad del ser humano, uno de los motivos fundamentales del humanismo chartriano. Así, a la celebración gozosa de un mundo bueno creado por Dios se une la alabanza a las obras humanas que constituyen una especie de prolongación del poder generativo divino.

Desde un planteamiento tan optimista respecto al mundo y al ser humano, no les resultó muy difícil a los filósofos de Chartres suavizar y matizar a la manera boeciana el rígido determinismo de la astrología antigua. Aunque ya la astrología árabe había iniciado esta tarea desde Abu Ma'shar, ${ }^{9}$ no obstante es en Chartres donde a partir de la doctrina de la creación estudiada a la luz del Timeo, se inicia una interpretación cristiana de la astrología. Así nos lo confirma un texto del propio Bernardo Silvestre, el Experimentarius, un pequeño manual de astrología que, sin ser nada original, le sirve apara introducir sus interpretaciones más personales. Así, en la Regula III A nos dice:

8 Fedón 62b ss. Vid. Cumont, F. «Comment Plotin détourna Porphyre du suicide» REG (1919) 113-120.

9 Vid. a este respecto la espléndida obra de R. Lemay Abu Ma'shar and Latin Aristotelianism in the Twelfth Century: Beirut. 1962. 
«El que creó el cielo y la tierra ha dado a algunas criaturas un poder por encima de otros como, por ejemplo, a los siete planetas a través de los cuales dispuso que en su movimiento pudieran determinar el cambio de todo el mundo y de sus elementos». ${ }^{10}$

Por tanto, la influencia planetaria sobre el mundo inferior está sujeta a la voluntad última del Creador, que, en su labor de conservación mundana se manifiesta como Providencia, utilizando sus propias obras como meros instrumentos para sus operaciones exteriores: ${ }^{11}$

«Nosotros, habiendo visto esto, no creemos que las estrellas y los planetas sean dioses ni los adoramos, sino que creemos y adoramos a su Creador, el Dios omnipotente. Creemos, en cambio, que ha proporcionado a los planetas el poder que los antiguos creían que prodecía de las mismas estrellas. Y creemos también que estos planetas tienen este mismo poder sobre las cosas, y que en su disposición establecen el destino de cada una, a no ser que el Señor, aplacado por una súplica, quiera convertir el mal en bien, u ofendido por una mala acción, el bien en mal. Los planetas, por su propia naturaleza, dominan sobre todas las cosas generadas y formadas, como ya dijimos anteriormente, y las disponen según su naturaleza y por ella preordenan el destino de todos los seres mortales, de manera que aquel que lo desee, pueda conocer en más de un caso su destino de acuerdo con la trayectoria y el poder de Dios». ${ }^{12}$

No se rechaza, pues, la predicción astrológica, siempre que se entienda como algo subordinado a la omnipotencia divina, de la que participa de manera especial la voluntad humana, por lo que ésta, en determinadas circunstancias, puede hacerle frente al Destino desde su propia libertad, tal y como nos lo ha mostrado la historia del Patricida. ${ }^{13}$

Francisco Tauste Alcocer

Cardenal Reig, 23, 3-2

E-08028 BARCELONA

10 Citamos por la edición del Experimentarius de Ch. S.F. Burnett publicado en AHDLMA 44(1977) 71-125 «What is the Experimentarius of Bernardus Silvestris», pág. 116.

11 Nuevamente habría que hacer referencia al libro IV de la Consolación de Boecio donde se plantea con gran lucidez las relaciones entre Providencia y Destino a partir de la tradición platónica. Para Boecio no se puede confundir el plano de la eternidad propio de la Providencia con el plano del tiempo en el que opera el Destino. Esta confusión de planos es propia del estoicismo mientras que el platonismo siempre tuvo claro que desde la jerarquía ontológica Providencia y Hado no son lo mismo. Cfr. Plotino Enéada III, 3,5: « Mas del conjunto de todas las cosas resulta una unidad y una sola providencia. Hay fatalidad, empero, a partir del nivel inferior, mientras que el nivel supremo es providencia pura. Porque todo lo que se contiene en el mundo inteligible es Razón o más que Razón, pues es Inteligencia o Alma pura; pero ya a partir de ahí, es providencia todo lo que proviene de allá, tanto lo que se contiene en el Alma pura como lo que de ella les viene a los animales. Ahora bien, la Razón viene dividiéndose en partes desiguales; por eso son desiguales los efectos que produce, como lo son en cada animal individual» (Trad. J. Igal. B. Clásica Gredos).

12 Op. cit. págs. 116-117.

13 Cfr. la nota 11. 